\title{
The accuration of parallel radiograph technique in measurement of alveolar crest resorption on removable orthodontic treatment
}

\author{
Aisa Nirmala Setyani*, Belly Sam* Elih** \\ *Department of Dentomaxillofacial Radiology, Faculty Of Dentistry Universitas Padjadjaran \\ **Department of Orthodontic, Faculty of Dentistry Universitas Padjadjaran
}

\begin{abstract}
Introduction: The parallel radiograph technique produce the accurate measurement so that it can be used to detect the small changing in the hard tissue. In the orthodontic treatment, the force which is given when the activation make the resorption of alveolar crest happen. The purpose of this study is to obtain data of the photo using radiograph periapikal parallel technique and the resorption of alveolar crest in orthodontic treatment during 3 weeks after the first activation. Methods: This quantitative descriptive study used the accidental sampling methode. The data was collected by using parallel radiograpy photo when the first aktivation of coil component in the removable orthodontic patient and 3 weeks after it. Then it was digitilized using the camera and proceeded by Easydent program. After that the tooth lenght of the first and second photos was counted. While to measure the a lveolar crest used the matematic proyection. Results: The result showed $p>0,05$ which meaned there was no significant differences of the tooth lenght between the first and second photos. The resorption of alveolar crest in this removable orthodontic treatment after the force was given during 3 weeks, was 0, $69899 \mathrm{~mm}$. Conclusion: The parallel radiography technique which is used in this study could be used in the measurement of such condition with reccurent time and the accurate result, and the resorption of the alveolar crest in the insisive central mandibule effected by removable orthodontic treatment was in normal range.
\end{abstract}

Keywords: Accuracy - alveolar bone resorption - coil - parallel radiograph -removable orthodontic

\section{INTRODUCTION}

Intraoral radiographic examination is imaging for the understanding of general dental practitioners. ${ }^{1}$ Intraoral radiography gives detailed visualisation, reaching approximately twenty lines every millimetre. A radiographic image can predict the pathologic condition, such as caries, tooth fracture, and periodontal lesion. It is easily accessible as well as relatively cheap. ${ }^{2,3}$ Periapical radiography is the most suitable radiograph to measure the loss of marginal bone loss. ${ }^{4}$

Optimal periapical radiographs are parallel and also a variety of deviations from the vertical angle in the measurement of marginal bone height. ${ }^{4}$ The identical periapical technique is a method recommended in showing changes in the bone, so that it is obtained with high accuracy, ${ }^{5}$ compared to bisectric technique that still shows dimensional distortion even though it's done well. ${ }^{6}$ 
The disadvantage of parallel periapical radiographic is the difficulty in the placement, and the patient would feel uncomfortable due to the device that is used to hold the film. This difficulty happens when the patient's mouth is small and patients with low palatal vault. ${ }^{6}$ A removable orthodontic appliance is an appliance or device fixed with multiple components to move the teeth as well as to act as an anchor. This appliance can be removed and worn by the users themselves. In a few cases, this removable orthodontic appliance has few advantages compared to the fixed device. For example, to correct unerupted incisal and canine teeth. ${ }^{7}$

The fixed orthodontic appliance has now well developed. However, the removable orthodontic appliance is still used mainly in Rumah Sakit Gigi dan Mulut Universitas Padjadjaran. (RSGM Unpad). Loss of alveolar bone and gingival recession occurs in patients who are undergoing orthodontic treatment. ${ }^{8}$ This is due to the presence of force applied on the teeth that causes movement. ${ }^{9}$ research is done by Cahaya, and her friends (2009) shows that Chondroitin 4 Sulphate ( C4S) is used as an indicator of alveolar bone resorption on research animals under orthodontic treatment. On the 14th day of applied force, the rate of $\mathrm{C} 4 \mathrm{~S}$ reaches peak level and reduces on the 21st day. In a nutshell, after the force has been applied, resorption of alveolar bone is maximal on the 14th day. Measurement of resorption of alveolar bone can be done by measuring the cementoenamel junction (CEJ) to alveolar bone crest or by comparing the height of the bone and the length of the root.10-11 In RSGM Unpad, the assessment of the condition of alveolar bone is by utilising bisectric periapical radiography. Meanwhile, parallel techniques with the usage of film holder are still less optimum. Before this issue, the author is interested in optimising the utilisation of identical periapical radiographic technology in measuring the alveolar bone crest in patients with the removable orthodontic appliance that undergoes acting force. ${ }^{12}$ The research aims to obtain the data on the accuracy of parallel periapical radiography of resorption of the mandibular central incisal alveolar bone crest that is undergoing removable orthodontic treatment in three weeks after the first activation.

\section{METHODS}

The type of research used in this research is quantitative descriptive with random sampling technique. The population of this study is removable orthodontic treatment patients with coil components, which has performed the first activation in March and April 2012 in RSGM Unpad with good oral hygiene, with coil component that would be activated in the mandibular central incisors, and willing to be a research respondent. Seven respondents who fulfilled the criteria were taken periapical photographs with parallel radiographic techniques twice, namely on the day of the first activation and three weeks after the first activation (during the fourth activation).

The calculation results are then tested statistically by using paired $t$ test (paired samples $t$ test) to see

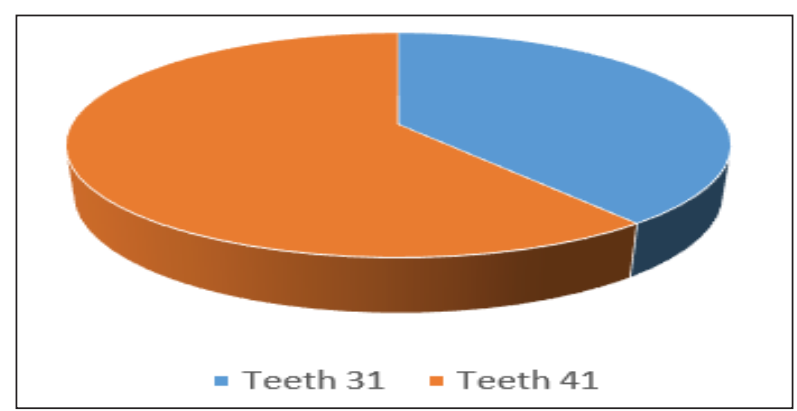

Diagram 1. Percentage Total Tooth Length and Difference Photo First and Second Photo Tooth Length Discord First and Second Photo

whether the difference between the first photo and the second photo is very significant or not. ${ }^{13}$ This can later show the level of confidence and accuracy of the parallel radiographic techniques used in this study. The results of the statistical calculations are presented in the table below: The difference or distortion that occurs in the use of parallel periapical techniques in this 
Tabel 1. Hasil Perhitungan uji $\mathrm{t}$ berpasangan (paired samples $\mathrm{t}$ test) dalam $\mathrm{mm}$

\begin{tabular}{ccccccc}
\hline & Rata-rata & Standar Deviasi & Minimum & Maksimum & Minimum Error & P-Value \\
\hline Gigi 31 & $-0,45714$ & 1,17453 & $-1,54340$ & 0,62912 & 0,44393 & 0,343 \\
Gigi 41 & $-0,15714$ & 1,81829 & $-1,83878$ & 1,52450 & 0,68725 & 0,827 \\
\hline $\mathbf{x}$ & & & & 0,585 \\
\hline
\end{tabular}

study can be caused by the limited film holder as a tool in this technique. As revealed in Woo's research. ${ }^{13}$ which uses bite-blocks with acrylic base material and rigid attachment between bite-blocks and tubes to obtain standardization in each individual. Likewise in research conducted. ${ }^{14}$ which uses silicone molding material in making bite-blocks for each individual, which can then be stored in the refrigerator and disinfected with the Deconex (Switzerland) material, so that in the next photo The bite-block can be reused as a standardization reference for the individual in the parallel radiographic periapical radiographic process.

Based on the results of the calculation of the Kolmogorov-Smirnov One-Sample Test it was found that the data were normally distributed, so the comparison test was use parametric, ie paired samples $t$ test. With a hypothesis if the Asymp Sig ( $p$-value)> 0.05 , it is said to be normal or not meaningful changes. The statistical calculation results in this study shown in table 1 illustrate that all $p$-values $>0.05$, so that the change in length from crown to apical teeth does not show significant changes between the first photo and also the second photo. Therefore the use of parallel periapical radiography techniques

Table 2 . Average resorption of Alveolar Bone Peak on Pressure and Non Pressure Pressure Side

\begin{tabular}{ccc}
\hline Tooth & $\begin{array}{c}\text { The side that gets } \\
\text { stressed }\end{array}$ & $\begin{array}{c}\text { The side that doesn't } \\
\text { get stressed }\end{array}$ \\
\hline & $(\mathrm{mm})$ & $(\mathrm{mm})$ \\
31 & .886178 & $-0,1838$ \\
41 & 0.51182 & 0.015563 \\
\hline $\mathrm{x}$ & .698999 & $-0,08412$ \\
\hline
\end{tabular}

or the orthodontic force and also the side that is not stressed. This pressure side is defined as the side corresponding to the movement in the direction carried out by the operator. If the tooth is moved in the mesial direction, the side that is under pressure is the mesial side, while the side that is not under pressure is the distal side and in the measurement of a certain condition in the tooth with repeated time or there is a time span between which shows accurate results, especially can be used to assess the state of the alveolar bone crest.

The difference in the dimensions of the photos in this study according to the results of statistical analysis is still within the normal range. Calculation of peak alveolar bone resorption values can be done by directly measuring the distance from the cemento enamel junction (CEJ) to the alveolar crest, but the difference in the dimensions of the photo, although small, will slightly affect the results of the image of the alveolar bone being absorbed.

Other calculations are also carried out to better show the peak resorption value of the alveolar bone, with mathematical conversion by projecting the height of the alveolar bone in the first photo in the second photo (A-PA ') first. The data is presented in tabular form for each tooth, namely teeth 31 and 41, and the height of the alveolar bone is measured distally and mesially. Table 2 . Average resorption of Alveolar Bone Peak on Pressure and Non Pressure Pressure Side The table above shows the resorption of the alveolar bone on the sides that is under pressure

vice versa. If the two regions are compared to the side that gets load, the resorption value of the alveolar bone is higher than the side that is not stressed.

In the area that is moved, there will be pressure and an increase in the diameter of blood cells in the space between ligaments which will obstruct blood flow. This results in the displacement of the teeth following the periodontal ligament space.

Periodontal ligament compression occurs in some areas where other parts will also be stretched. In this process, a chemical reaction will then occur, which will then induce a response of the cell. In the movement of tipping, the gear will move according to the pivot point. In this case, the cell 
will react to the apex of the alveolar bone on the movable side (the opposite side to where the active component is placed) and also on the apical side of the opposite side (the immovable side). ${ }^{15}$

\section{RESULTS}

Parallel periapical radiography technique produces radiographic images with high sharpness quality. It can minimise geometric distortion, so it is recommended as the first choice for all cases with periapical projection indications.

Parallel techniques performed on jaws that still have teeth can produce radiographs with minimal distortion. Another advantage is that this technique is easy to obtain, and the price is relatively affordable. ${ }^{12}$

Periapical radiography can also experience distortion and enlargement of the image, even though it uses the parallel technique. This study also illustrates the difference in crown apical length between the first image $(A-I)$ and the second image (A-I').

This happened to all the samples taken, with an average difference of $4.2 \%$. In this study, it is found that the magnitude of the image distortion that occurred was smaller than the survey conducted by Mehdizadeh (1997) whose distortion was $9.4 \% .{ }^{13}$ The results of the different lengths of each tooth can be presented in the diagram below.

\section{CONCLUSION}

The parallel periapical radiography technique applied in this study can be used in the measurement of a particular condition with repeated time with accurate results and alveolar crest resorption that occurs in the mandibular central incisors due to removable orthodontic treatment is still in normal range.

\section{REFERENCES}

1. White SC, Goaz PW, Oral Radiology Principle and Interpretation. St. Louis Mosby Inc. 1994

2. Kunzel $A D$, Scherkowski R, Willers, Becker $J$. Visually detectable resolution of intraoral dental films. Dent Rad J. 2003;32(1):385-389.

3. Vasconcelos KF, Evangelista KM, Rodrigues CD,
Estrela C, de Sousa TO, Silva MAG. Detection of periodontal bone loss using cone beam CT and intraoral. Dent Rad J. 2012;41(1):64-69

4. Lofthag $\mathrm{H}$, Lindh R, Petersson A. Radiographic assessment of the marginal bone level after implant treatment: a comparison of periapical and Scanora detailed narrow beam radiography. Dentomax fac Rad J. 32(1):97103.

5. Formoso NFB. Rilo MJ, Mora IM, Silva, Santana U. A paralleling technique modification to determine the bone crest level around dental implants. Dentomax fac Rad J. 2011;40(1) 385-389.

6. Frommer HH, Savage JJS. Radiology for The Dental Professional ed 8. Missouri : Mosby, Inc. 2005.

7. Isaacson KG, Muir JD, Reed RT. Removable Orthodontic Appliances. India Elsevier. 2002. 1-7, 11-13, 15-17.

8. Lau PY, Wong RW. Risks and complications in orthodontic treatment. Hongkong Dental Journal, 2006;3(1)15-22. Available online at http://ncbi.nlm.nih.gov (diakses 16 November 2011).

9. Lindauer SJ. The basics of orthodontic mechanics. in Seminars in Orthodontics, 2001;7(1)2-15

10. Pierro VSS, de Souza IPR, Luiz RR, Barcelos R, Moraes RS. Reliability of two methods for measurement of alveolar bone level in children. Dent Rad J. 2008;37(1)34-39.

11. Salonen LWE, Frithiof L, Wouters FR, Hellden LB. Marginal alveolar bone height in an adult swedish population. A radiographic crosssectional epidemiologic study. J Clin Period. 1991;18(1)223-232.

12. Yunus $B$. Pengukuran tulang rahang dengan ctscan sebagai faktor koreksi terhadap radiografi gigi konvensional untuk pemasangan implan gigi. JST Kesehatan. April 2011;1(1):10-18.

13. Moradi JF. Poorsafar M. Khoshhal. A comparison of two radiographic technique to determine the distance between alveolar bone crest and cementoenamel junction in patient with chronic periodontitis. DJH. 2010;1(2)1-7

14. Woo BM, Zee KY, Chan FH, Corbet EF. In vitro calibration and validation of a digital subtraction radiography system using scanned images. J Clin Periodontol 2003;30:114-8. 
15. Khojastehpaur LH, Khosropanah, MJ, Kharazifard. The effect of bite registration on the reproducibility of parallel periapical radiographs obtained with two month intervals. J Dent, Tehran University of Medical Sciences. 2006;3(2). 